ISSN 1029-8940 (Print)

ISSN 2524-230X (Online)

УДК 634.737:581.5:581.522.4(476)

Поступила в редакцию 27.04.17

Received 27.04.17

\author{
Ж. А. Рупасова ${ }^{1}$, И. М. Гаранович ${ }^{1}$, Т. В. Шпитальная ${ }^{1}$, Т. И. Василевская ${ }^{1}$, \\ Н. Б. Криницкая ${ }^{1}$ Т. В. Фролова ${ }^{2}$, А. В. Архаров ${ }^{1}$ \\ ${ }^{1}$ Центральный ботанический сад НАН Беларуси, Минск, Республика Беларусь \\ ${ }^{2}$ Институт плодоводства, пос. Самохваловичи, Республика Беларусь

\section{ФЕНОЛЬНЫЙ КОМПЛЕКС ПЛОДОВ ИНТРОДУЦИРОВАННЫХ ВИДОВ СЕМЕЙСТВА АКТИНИДИЕВЫЕ (АСТINIDIАСЕАЕ) В УСЛОВИЯХ БЕЛАРУСИ}

Аннотация. Приведены результаты сравнительного исследования содержания основных групп биофлавоноидов и дубильных веществ в плодах дикорастущей формы и 5 сортов Actinidia arguta (Киевская крупноплодная, Киевская гибридная, Ласунка, Пурпурная садовая и Сентябрьская), а также в плодах дикорастущей формы и 8 сортов Actinidia kolomikta (Превосходная, Ароматная, Достойная, Однодомная, Сентябрьская, ВИР-1, Вафельная и Ботаническая). Показано, что отличительной особенностью биофлавоноидного комплекса плодов обоих видов являлось отсутствие в его составе собственно антоцианов при доминировании у Actinidia arguta лейкоантоцианов, у актинидии коломикта лейкоантоцианов и флавонолов. Селекционное улучшение обоих видов актинидии способствовало ингибированию в плодах биосинтеза биофлавоноидов, особенно у Actinidia arguta, у которой минимальные потери данных соединений установлены у сортов Киевская крупноплодная, Киевская гибридная и Ласунка. У Actinidia kolomikta наиболее высоким содержанием в плодах витаминов Р, превосходящим таковое у природной формы, характеризовались три сорта Достойная, Однодомная и Вафельная.

Ключевые слова: актинидия аргута, актинидия коломикта, сорта, плоды, лейкоантоцианы, катехины, флавонолы, биофлавоноиды, дубильные вещества

Для цитирования: Фенольный комплекс плодов интродуцированных видов семейства Актинидиевые (Actinidiaceae) в условиях Беларуси / Ж. А. Рупасова [и др.] // Вес. Нац. акад. навук Беларусі. Сер. біял. навук. - 2018. - Т. 63, № 1. C. $39-45$.

Zh. A. Rupasova, I. M. Garanovich, T. V. Shpitalnaya, T. I. Vasilevskaya, N. B. Krinitskaya, T. V. Frolova, A. V. Arkharov

${ }^{1}$ Central Botanical Garden of the NAS of Belarus, Minsk, Republic of Belarus

${ }^{2}$ Institute for Fruit Growing, Samochvalovichi, Republic of Belarus

\title{
PHENOL COMPLEX OF FRUITS OF INTRODUCED SPECIES OF THE ACTINIDIACEAE FAMILY IN CONDITIONS OF BELARUS
}

\begin{abstract}
The article presents results of a comparative study of the content of main groups of bioflavonoids and tannins in fruits of the wild form and 5 sorts of Actinidia arguta - Kievskaya krupnoplodnaya, Kievskaya hybridnaya, Lasunka, Purpurnaya sadovaya and Sentyabrskaya, as well as the wild form and 8 sorts of Actinidia kolomikta - Prevoskhodnaya, Aromatnaya, Dostoynaya, Odnodomnaya, Sentyabrskaya, VIR-1, Vafelnaya and Botanicheskaya. It has been shown that a characteristic feature of the bioflavonoid complex of fruits of both the species was absence of true anthocyanins in its composition with leucoanthocyanins dominating in Actinidia arguta and leucoanthocyanins and flavonols in Actinidia kolomikta. Selection improvements of both the species of Actinidia led to inhibition of bioflavonoid biosynthesis in fruits, especially fruits of Actinidia arguta. Minimal losses of the given compounds have been shown by sorts Kievskaya krupnoplodnaya, Kievskaya hybridnaya and Lasunka. Three sorts of Actinidia kolomikta - Dostoynaya, Odnodomnaya and Vafelnaya were characterized by the highest content of P-vitamins in fruits which exceeds the figures for the natural form.

Keywords: Actinidia arguta, Actinidia kolomikta, sorts, fruits, leucoanthocyanins, catechines, flavonols, bioflavonoids, tannins

For citation: Rupasova Zh. A., Garanovich I. M., Shpitalnaya T. V., Vasilevskaya T. I., Krinitskaya N. B., Frolova T. V., Arkharov A. V. Phenol complex of fruits of indroduced species of the Actinidiaceae family in conditions of Belarus. Vestsi Natsyyanal'nai akademii navuk Belarusi. Seryya biyalagichnych navuk = Proceedings of the National Academy of Sciences of Belarus. Biological series, 2018, vol. 63, no. 1, pp. 39-45 (in Russian).
\end{abstract}

Введение. В связи с многогранностью позитивного действия на человеческий организм растительных полифенолов и возможностью их использования в пищевых и медицинских целях [1] в последние десятилетия приоритетное значение придается исследованиям, связанным с количественной и качественной оценкой биофлавоноидного комплекса плодов и его антиоксидантной активности. Особое место в ряду интродуцентов, являющихся перспективными источниками витаминов Р, 
занимают наиболее распространенные в практике любительского садоводства популярные виды сем. Actinidiaceae - актинидия аргута (Actinidia arguta Planch. ex Mig) и актинидия коломикта (Actinidia kolomikta Maxim.). По нашим предварительным оценкам, сырьевые части этих растений в условиях Беларуси характеризуются значительным накоплением широкого спектра физиологически ценных соединений, в том числе биофлавоноидов, что делает их весьма привлекательными для комплексного практического использования, особенно в связи с последствиями аварии на Чернобыльской АС.

Вместе с тем в научной литературе практически отсутствует информация о содержании в плодах актинидий витаминов Р, что, на наш взгляд, является серьезным пробелом в исследовании полезных свойств этих интродуцентов. При этом значительный научный интерес представляет анализ состава биофлавоноидного комплекса их плодов с целью выявления межвидовых различий и выведения сортов с повышенным содержанием этих физиологически ценных соединений.

Цель работы - выявить сорта Actinidia arguta и Actinidia kolomikta с наиболее высоким содержанием в плодах биофлавоноидов.

Объекты и методы исследований. Исследования выполнены в 2015-2016 гг. на основе базовых коллекций представителей сем. Actinidiaceae Центрального ботанического сада НАН Беларуси и РУП «Институт плодоводства» (Минская обл.), находящихся на территории центральной агроклиматической зоны Беларуси в районе распространения легких песчаных дерново-подзолистых почв. Погодные условия в годы наблюдений характеризовались повышенным температурным фоном и относительно благоприятным режимом выпадения атмосферных осадков в течение вегетационного периода.

В качестве объектов исследований были выбраны плоды дикорастущей формы и 5 сортов Actinidia arguta - Киевская крупноплодная, Киевская гибридная, Ласунка, Пурпурная садовая и Сентябрьская, а также плоды дикорастущей формы и 8 сортов Actinidia kolomikta - Превосходная, Ароматная, Достойная, Однодомная, Сентябрьская, ВИР-1, Вафельная и Ботаническая. Сравнительную оценку состава биофлавоноидного комплекса плодов данных объектов осуществляли путем определения в высушенных при температуре $60{ }^{\circ} \mathrm{C}$ пробах растительного материала суммарного содержания антоциановых пигментов - по методу T. Swain, W. E. Hillis [2] (с построением градуировочной кривой по кристаллическому цианидину, полученному из плодов аронии черноплодной и очищенному по методике Ю. Г. Скориковой и Э. А. Шафтан [3]); собственно антоцианов и суммы катехинов (с использованием ванилинового реактива) - фотоэлектроколориметрическим методом $[4,5]$; суммы флавонолов (в пересчете на рутин) - спектрофотометрическим методом [5]; дубильных веществ - титрометрическим методом Левенталя [6]. Все аналитические определения выполнены в 3-кратной биологической повторности. Данные статистически обработаны с использованием программы Excel.

Результаты и их обсуждение. При проведении биохимического скрининга новых сортов Actinidia arguta и Actinidia kolomikta в качестве эталонов сравнения были приняты распространенные в Беларуси природные формы данных видов.

Впервые проведенное исследование биофлавоноидного комплекса плодов новых интродуцированных сортов актинидии аргута выявило довольно высокое содержание в них полифенолов, хотя и уступавшее примерно вдвое таковому в плодах наиболее обогащенных ими видов - клюквы крупноплодной и голубики высокорослой, но вполне сопоставимое с таковым в плодах рябины обыкновенной и калины обыкновенной [7]. Диапазон варьирования в таксономическом ряду общего количества этих чрезвычайно ценных биологически активных соединений в плодах актинидии в двулетнем цикле наблюдений составлял $3863,3-4856,8$ мг\% сухой массы (табл. 1) при максимальном его значении у природной формы и минимальном у сорта Сентябрьская и характеризовался расхождением крайних позиций в 1,3 раза, что свидетельствовало о наличии генотипических различий в их накоплении. Особенностью Р-витаминного комплекса плодов данного вида, как и ранее изученного нами Chaenomeles maulei [7], явилось отсутствие в его составе группы собственно антоцианов при доминировании лейкоантоцианов, общая доля которых при содержании 2366,0-2825,3 мг\% достигала 54-61 \% от общего количества полифенолов. 
Вместе с тем доля флавонолов в составе биофлавоноидного комплекса плодов актинидии аргута, составлявшая 21-24 \% при содержании 864,6-1017,4 мг\%, у большинства таксонов оказалась несколько выше, чем у катехинов, на долю которых приходилось $15-25 \%$ при содержании $593,7-1100,7$ мг\%.

Однако, несмотря на генотипические различия в содержании основных групп биофлавоноидов в плодах исследуемых таксонов актинидии аргута, наблюдалось заметное сходство в составе их Р-витаминного комплекса, определяемое подобием соотношения в нем отдельных компонентов. При этом содержание дубильных веществ в сухой массе плодов было сопоставимо с таковым у клюквы крупноплодной и голубики высокорослой [7] и изменялось в таксономическом ряду от 1,39 до $3,10 \%$ (табл. 1).

Т а б л и ц а 1. Содержание фенольных соединений в сухой массе плодов интродуцированных таксонов Actinidia arguta и Actinidia kolomikta в двулетнем цикле наблюдений

$\mathrm{T}$ a $\mathrm{b} 1 \mathrm{e}$ 1. The content of phenolic compounds in dry mass of fruits of introduced taxa and Actinidia kolomikta, Actinidia arguta in two years cycle observations

\begin{tabular}{|c|c|c|c|c|c|c|c|c|c|c|}
\hline \multirow{3}{*}{ Таксон } & \multicolumn{8}{|c|}{ Биофлавоноиды, мг\% } & \multirow{2}{*}{\multicolumn{2}{|c|}{$\begin{array}{l}\text { Дубильные } \\
\text { вещества, \% }\end{array}$}} \\
\hline & \multicolumn{2}{|c|}{ Лейкоантоцианы } & \multicolumn{2}{|c|}{ Катехины } & \multicolumn{2}{|l|}{ Флавонолы } & \multicolumn{2}{|l|}{ Сумма } & & \\
\hline & $\mathrm{X} \pm \mathrm{st}$ & $t$ & $\mathrm{X} \pm \mathrm{st}$ & $t$ & $\mathrm{X} \pm \mathrm{st}$ & $\mathrm{t}$ & $\mathrm{X} \pm \mathrm{st}$ & $\mathrm{t}$ & $\mathrm{X} \pm \mathrm{st}$ & $t$ \\
\hline \multicolumn{11}{|c|}{ Actinidia arguta } \\
\hline $\begin{array}{l}\text { Природная } \\
\text { форма (st) }\end{array}$ & $2825,3 \pm 45,9$ & & $1014,0 \pm 3,5$ & & $1017,4 \pm 8,8$ & & $4856,8 \pm 45,6$ & & $1,92 \pm 0,05$ & \\
\hline $\begin{array}{l}\text { Киевская } \\
\text { крупноплодная }\end{array}$ & $2418,0 \pm 60,0$ & $-5,4^{*}$ & $1100,7 \pm 31,2$ & $2,8^{*}$ & $951,9 \pm 2,7$ & $-7,1^{*}$ & $4470,6 \pm 31,7$ & $-6,9^{*}$ & $3,10 \pm 0,13$ & $8,4^{*}$ \\
\hline $\begin{array}{l}\text { Киевская } \\
\text { гибридная }\end{array}$ & $2600,0 \pm 30,0$ & $-4,1^{*}$ & $862,3 \pm 11,5$ & $-12,7^{*}$ & $960,7 \pm 13,7$ & $-3,5^{*}$ & $4423,0 \pm 22,0$ & $-8,6^{*}$ & $2,62 \pm 0,10$ & $6,4^{*}$ \\
\hline Ласунка & $2652,0 \pm 30,0$ & $-3,2^{*}$ & $858,0 \pm 15,0$ & $-10,1^{*}$ & $908,3 \pm 30,6$ & $-3,4^{*}$ & $4418,3 \pm 42,9$ & $-7,0^{*}$ & $2,16 \pm 0,01$ & $5,0^{*}$ \\
\hline $\begin{array}{l}\text { Пурпурная } \\
\text { садовая }\end{array}$ & $2366,0 \pm 30,0$ & $-8,4^{*}$ & $593,7 \pm 11,5$ & $-35,1^{*}$ & $938,8 \pm 27,0$ & $-2,8^{*}$ & $3898,5 \pm 34,5$ & $-16,7^{*}$ & $2,54 \pm 0,03$ & $11,2^{*}$ \\
\hline Сентябрьская & $2366,0 \pm 30,0$ & $-8,4^{*}$ & $632,7 \pm 17,3$ & $-21,6^{*}$ & $864,6 \pm 13,1$ & $-9,7^{*}$ & $3863,3 \pm 47,8$ & $-15,0^{*}$ & $1,39 \pm 0,03$ & $-8,8^{*}$ \\
\hline \multicolumn{11}{|c|}{ Actinidia kolomikta } \\
\hline $\begin{array}{l}\text { Природная } \\
\text { форма (st) }\end{array}$ & $910,0 \pm 30,0$ & & $541,7 \pm 11,5$ & & $1454,1 \pm 7,6$ & & $2905,8 \pm 30,4$ & & $3,51 \pm 0,01$ & \\
\hline Превосходная & $937,4 \pm 15,1$ & 0,8 & $478,1 \pm 5,2$ & $-5,0^{*}$ & $951,9 \pm 19,0$ & $-24,5^{*}$ & $2367,5 \pm 16,7$ & $-15,5^{*}$ & $2,87 \pm 0,02$ & $-24,8^{*}$ \\
\hline Ароматная & $1022,7 \pm 20,4$ & $3,1^{*}$ & $494,0 \pm 3,5$ & $-4,0^{*}$ & $1231,4 \pm 7,6$ & $-20,8^{*}$ & $2748,1 \pm 17,2$ & $-4,5^{*}$ & $2,10 \pm 0,01$ & $-86,3^{*}$ \\
\hline Достойная & $1300,0 \pm 15,0$ & $11,6^{*}$ & $567,7 \pm 11,5$ & 1,6 & $1248,9 \pm 19,0$ & $-10,0^{*}$ & $3116,5 \pm 7,4$ & $6,7^{*}$ & $2,08 \pm 0,01$ & $-68,4^{*}$ \\
\hline Однодомная & $1274,0 \pm 30,0$ & $8,6^{*}$ & $663,0 \pm 7,5$ & $8,9^{*}$ & $1423,5 \pm 11,6$ & $-2,2$ & $3360,5 \pm 22,9$ & $11,9^{*}$ & $2,54 \pm 0,03$ & $-34,2^{*}$ \\
\hline Сентябрьская & $1378,0 \pm 15,0$ & $13,9^{*}$ & $602,3 \pm 15,6$ & $3,1^{*}$ & $1017,4 \pm 19,0$ & $-21,3^{*}$ & $2997,8 \pm 45,8$ & 1,7 & $2,60 \pm 0,01$ & $-55,7^{*}$ \\
\hline ВИР-1 & $1118,0 \pm 30,0$ & $4,9^{*}$ & $563,3 \pm 8,7$ & 1,5 & $1272,9 \pm 19,4$ & $-8,7^{*}$ & $2954,2 \pm 17,1$ & 1,4 & $2,50 \pm 0,05$ & $-20,1^{*}$ \\
\hline Вафельная & $1222,0 \pm 30,0$ & $7,3^{*}$ & $702,0 \pm 15,0$ & $8,5^{*}$ & $1471,6 \pm 19,0$ & \begin{tabular}{|l|}
0,9 \\
\end{tabular} & $3395,6 \pm 41,3$ & $9,5^{*}$ & $3,49 \pm 0,01$ & $-1,7$ \\
\hline Ботаническая & $1092,0 \pm 15,0$ & $5,4^{*}$ & $624,0 \pm 13,0$ & $4,8^{*}$ & $869,0 \pm 11,6$ & $-42,4^{*}$ & $2585,0 \pm 37,1$ & $-6,7^{*}$ & $2,08 \pm 0,01$ & $-68,4^{*}$ \\
\hline
\end{tabular}

П р и м е ч а н и е. ${ }^{*}$ - статистически значимые по $t$-критерию Стьюдента различия с природной формой при $p<0,05$.

Исследуемые таксоны актинидии коломикта характеризовались сравнительно высоким, хотя и уступавшим в несколько раз голубике высокорослой и клюкве крупноплодной, но вполне сопоставимым с таковым у рябины обыкновенной и кизила настоящего [7, 8], содержанием в плодах биофлавоноидов, изменявшимся в таксономическом ряду в диапазоне значений от 2367,5 мг\% сухой массы у районированного сорта Превосходная до 3360,5-3395,6 мг\% у сортов Однодомная и Вафельная (табл. 1). Расхождение крайних позиций в 1,4 раза (как и у актинидии аргута) свидетельствовало о существенных генотипических различиях в накоплении данных соединений. Заметим, однако, что плоды сортового материала актинидии аргута характеризовались все же более высоким, чем у сортов актинидии коломикта, общим содержанием биофлавоноидов, тогда как у природных форм данных видов наблюдалась противоположная картина. 
Вместе с тем, как и у актинидии аргута, отличительной особенностью биофлавоноидного комплекса плодов актинидии коломикта являлось отсутствие в его составе собственно антоцианов. Но доминирующее положение в нем, в отличие от первого вида, принадлежало уже двум основным группам полифенолов - лейкоантоцианам и флавонолам, содержание которых варьировалось в таксономическом ряду в диапазонах $910,0-1378,0$ и $869,0-1471,6$ мг\% сухой массы соответственно. Доля лейкоантоцианов в составе Р-витаминного комплекса плодов составляла 31-46 \%, флавонолов - 34-50 \%. При этом у большинства таксонов актинидии коломикта отмечено превышение доли флавонолов над таковой лейкоантоцианов на 4-19 \%, наиболее значительное у природной формы, и лишь у сортов Достойная, Ботаническая и особенно Сентябрьская наблюдалась противоположная картина при относительных различиях в пределах 2-12\%. Нетрудно убедиться в наличии существенных межвидовых различий у актинидии аргута и актинидии коломикта в соотношении в плодах количества лейкоантоцианов и флавонолов. Если у первого вида оно варьировалось в сортовом ряду от 2,5 до 2,9 , то у второго было близко к 1 . Доля катехинов в составе биофлавоноидного комплекса плодов сортов актинидии коломикта была схожа с таковой актинидии аргута и не превышала 18-24 \% при содержании в сухой массе 478,1-702,0 мг\%. При этом содержание дубильных веществ было сопоставимо с таковым в плодах других малораспространенных культур садоводства [7] и варьировалось в таксономическом ряду в диапазоне от 2,08 до $3,51 \%$ сухого вещества (табл. 1).

Как следует из табл. 2 , у тестируемых сортов обоих видов актинидии установлены весьма существенные различия с их природными формами в содержании в плодах фенольных соединений. Так, все сорта актинидии аргута уступали природной форме на 8-21 \% в общем содержании в плодах биофлавоноидов, при этом наибольшие различия отмечены у сортов Пурпурная садовая и Сентябрьская. Наиболее контрастная картина подобных различий наблюдалась для катехинов, содержание которых в плодах сортового материала, особенно у упомянутых выше таксонов, оказалось ниже, чем у природной формы, на 15-42 \%. Исключением из этого ряда явился лишь сорт Киевская крупноплодная, для которого было показано более активное накопление в плодах данных соединений (на $9 \%$ ). Отставание сортов актинидии аргута от природной формы в содержании в плодах лейкоантоцианов и флавонолов составляло 6-16 \%. При этом все сорта данного вида, кроме сорта Сентябрьская, превосходили ее на 13-62 \% в накоплении дубильных веществ.

Т а б л и ц а 2. Относительные различия в содержании в плодах фенольных соединений между интродуцированными сортами Actinidia arguta и Actinidia kolomikta и их природными формами, \%

$\mathrm{T}$ a $\mathrm{b} 1 \mathrm{e} 2$. Relative differences in the content of phenolic compounds in fruit between the introduced varieties of Actinidia arguta and Actinidia kolomikta and their natural form in years of research, \%

\begin{tabular}{|c|c|c|c|c|c|}
\hline Показатель & Лейкоантоцианы & Катехины & Флавонолы & Сумма биофлавоноидов & Дубильные вещества \\
\hline \multicolumn{6}{|c|}{ Actinidia arguta } \\
\hline Киевская крупноплодная & $-14,4$ & $+8,6$ & $-6,4$ & $-8,0$ & $+61,5$ \\
\hline Киевская гибридная & $-8,0$ & $-15,0$ & $-5,6$ & $-8,9$ & $+36,5$ \\
\hline Ласунка & $-6,1$ & $-15,4$ & $-10,7$ & $-9,0$ & $+12,5$ \\
\hline Пурпурная садовая & $-16,3$ & $-41,5$ & $-7,7$ & $-19,7$ & $+32,3$ \\
\hline Сентябрьская & $-16,3$ & $-37,6$ & $-15,0$ & $-20,5$ & $-27,6$ \\
\hline \multicolumn{6}{|c|}{ Actinidia kolomikta } \\
\hline Превосходная & - & $-11,7$ & $-34,5$ & $-18,5$ & $-18,2$ \\
\hline Ароматная & $+12,4$ & $-8,8$ & $-15,3$ & $-5,4$ & $-40,2$ \\
\hline Достойная & $+42,9$ & - & $-14,1$ & $+7,3$ & $-40,7$ \\
\hline Однодомная & $+40,0$ & $+22,4$ & - & $+15,6$ & $-27,6$ \\
\hline Сентябрьская & $+51,4$ & $+11,2$ & $-30,0$ & - & $-25,9$ \\
\hline ВИР-1 & $+22,9$ & - & $-12,5$ & - & $-28,8$ \\
\hline Вафельная & $+34,3$ & $+29,6$ & - & $+16,9$ & - \\
\hline Ботаническая & $+20,0$ & $+15,2$ & $-40,2$ & $-11,0$ & $-40,7$ \\
\hline
\end{tabular}

П р и м е ч а н и е. Прочерк означает отсутствие статистически значимых по $t$-критерию Стьюдента различий с природной формой при $p<0,05$. 
Несколько иная картина подобных различий характеризовала актинидию коломикта, у которой плоды всех сортов, кроме сорта Превосходная, оказались на $12-51$ \% богаче лейкоантоцианами, чем плоды природной формы, при наибольших различиях у сорта Сентябрьская. Для половины тестируемых объектов было показано также на 11-30 \% более высокое, чем у нее, содержание в плодах катехинов, обладающих химическим сродством с лейкоантоцианами [9]. При этом лишь у сортов Превосходная и Ароматная оно оказалось на 9-12 \% ниже, чем у природной формы, на фоне сопоставимости с ней параметров их накопления у сортов Достойная и ВИР-1. В отличие от данных соединений, содержание флавонолов в плодах сортового материала в подавляющем большинстве случаев уступало таковому у природной формы на $13-40 \%$, особенно у сорта Ботаническая. Лишь у сортов Однодомная и Вафельная расхождений с ней по данному признаку выявлено не было (табл. 2). Неоднозначные тенденции в характере различий тестируемых сортов актинидии коломикта с природной формой в содержании в плодах основных групп биофлавоноидов проявились также в различиях по общему количеству витаминов Р. Оказалось, что лишь три сорта - Достойная, Однодомная и Вафельная характеризовались на 7-17 \% более значительным, чем у природной формы, накоплением последних, тогда как в остальных случаях их суммарное содержание либо уступало таковому в плодах природной формы актинидии на 5-19 \%, либо было сопоставимо с ним. Что касается дубильных веществ, то их содержание в плодах всех тестируемых сортов актинидии коломикта, кроме сорта Вафельная, оказалось ниже, чем у природной формы, на $18-41 \%$.

Как видим, селекционный процесс оказал неоднозначное влияние на биосинтез фенольных соединений в плодах обоих видов актинидии. При этом селекционное улучшение актинидии аргута сопровождалось ингибированием в них биосинтеза витаминов Р, что косвенно свидетельствовало о снижении уровня их антиоксидантной активности, наиболее выраженном у сортов Пурпурная садовая и Сентябрьская. У остальных тестируемых сортов данного вида - Киевская крупноплодная, Киевская гибридная и Ласунка - подобное снижение проявилось в меньшей или примерно равной степени. Что касается актинидии коломикта, то сортовой материал, в отличие от природной формы, характеризовался преимущественно более высоким содержанием в плодах лейкоантоцианов и катехинов, но обладал более низким содержанием флавонолов, что так же, как и у актинидии аргута, способствовало снижению в них общего количества биофлавоноидов. При этом лидирующее положение в таксономическом ряду по содержанию в плодах витаминов Р, превосходящему таковое у природной формы, принадлежало трем сортам данного вида Достойная, Однодомная и Вафельная.

Заключение. Сравнительное исследование содержания основных групп биофлавоноидов и дубильных веществ в плодах дикорастущей формы и 5 сортов Actinidia arguta - Киевская крупноплодная, Киевская гибридная, Ласунка, Пурпурная садовая и Сентябрьская, а также в плодах дикорастущей формы и 8 сортов Actinidia kolomikta - Превосходная, Ароматная, Достойная, Однодомная, Сентябрьская, ВИР-1, Вафельная и Ботаническая показало, что суммарное количество витаминов Р в первом случае составляло $3863,3-4856,8$ мг\% сухой массы, во втором 2367,5-3395,6 мг\%. Отличительной особенностью биофлавоноидного комплекса плодов обоих видов являлось отсутствие в его составе собственно антоцианов. Плоды сортового материала актинидии аргута характеризовались более высоким, чем у актинидии коломикта, общим содержанием биофлавоноидов, в то время как у природных форм данных видов наблюдалась противоположная картина. Абсолютно доминирующее положение в составе Р-витаминного комплекса актинидии аргута принадлежало лейкоантоцианам, у актинидии коломикта - лейкоантоцианам и флавонолам. Селекционное улучшение обоих видов актинидии преимущественно способствовало ингибированию в плодах биосинтеза биофлавоноидов, особенно у актинидии аргута, у которой минимальные потери данных соединений установлены у сортов Киевская крупноплодная, Киевская гибридная и Ласунка. У актинидии коломикта наиболее высоким содержанием в плодах Р-витаминов, превосходящим таковое у природной формы, характеризовались три сорта Достойная, Однодомная и Вафельная. 


\section{Список использованных источников}

1. Howell, A. B. Update on health benefits of cranberry and blueberry / A. B. Howell // Acta Hort. - 2009. - Vol. 810. P. 779-784.

2. Swain, T. The phenolic constituents of Prunus Domenstica. 1. The quantitative analysis of phenolic constituents / T. Swain, W. Hillis // J. Sci. Food Agric. - 1959. - Vol. 10, N 1. - P. 63-68.

3. Скорикова, Ю. Г. Методика определения антоцианов в плодах и ягодах / Ю. Г. Скорикова, Э. А. Шафтан // Тр. 3-го Всесоюз. семинара по биологически активным (лечебным) веществам плодов и ягод. - Свердловск, 1968. C. $451-461$.

4. Методика определения антоцианов в плодах аронии черноплодной / В. Ю. Андреева [и др.] // Фармация. 2013. - № 3. - С. 19-21.

5. Методы биохимического исследования растений / под ред. А. И. Ермакова. - 3-е изд., перераб. и доп. - Ленинград : Агропромиздат, ЛО, 1987. - 430 с.

6. Определение содержания дубильных веществ в лекарственном растительном сырье // Государственная фармакопея Союза Советских Социалистческих Республик / М-во здравоохранения СССР. - М., 1987. - Вып. 1 : Общие методы анализа. - С. 286-287.

7. Биохимический состав плодов малораспространенных культур садоводства в Беларуси / Ж. А. Рупасова [и др.]. - Минск : Беларус. навука, 2014. - 315 с.

8. Формирование биохимического состава плодов видов семейства Ericaceae (Вересковые) при интродукции в условиях Беларуси / Ж. А. Рупасова [и др.]; под ред. акад. В. И. Парфенова. - Минск : Беларус. навука, 2011. $307 \mathrm{c}$.

9. Карабанов, И. А. Флавоноиды в мире растений / И. А. Карабанов. - Минск : Ураджай, 1981. - 80 с.

\section{References}

1. Howell A. B. Update on health benefits of cranberry and blueberry. Acta Horticulturae, 2009, vol. 810, pp. 779-784. DOI: $10.17660 /$ ActaHortic.2009.810.104

2. Swain T., Hillis W. The phenolic constituents of Prunus Domenstica. 1. The quantitative analysis of phenolic. Journal of the Science of Food and Agriculture, 1959, vol. 10, no. 1, pp. 63-68. DOI: 10.1002/jsfa.2740100110

3. Skorikova Iu. G., Shaftan E. A. Method for the determination of anthocyanins in fruits and berries. Trudy 3-go Vsesoiuznogo seminara po biologicheski aktivnym (lechebnym) veshchestvam plodov i iagod [Proceedings of the 3rd All-Union seminar on biologically active (medicinal) substances of fruits and berries]. Sverdlovsk, 1968, pp. 451-461 (in Russian).

4. Andreeva V. Iu., Kalinkina G. I., Kolomiets N. E., Isaikina N. V. Method for the determination of anthocyanins in fruits of chokeberry fennel. Farmatsiia [Pharmacy], 2013, no. 3, pp. 19-21 (in Russian).

5. Methods of biochemical research of plants, in Ermakov A. I. (ed.), 3rd edition, revised and enlarged. Leningrad, Agropromizdat, LO Publ., 1987. 430 p. (in Russian).

6. Determination of the content of tannins in medicinal plant raw materials. Gosudarstvennaya farmakopeya Soiuza Sovetskikh Sotsialistcheskikh Respublik. Vyp. 1 : Obshchie metody analiza [State Pharmacopoeia of the Union of Soviet Socialist Republics. Iss. 1: General methods of analysis]. Moscow, 1987, pp. $286-287$ (in Russian).

7. Rupasova Zh. A., Garanovich I. M., Shpital'naya T. V., Vasilevskaya T. I., Pavlovskii N. B., Krinitskaya N. B. Biochemical composition of fruit of horticultural crops in Belarus. Minsk, Belaruskaia navuka Publ., 2014. 315 p. (in Russian).

8. Rupasova Zh. A., Garanovich I. M., T. V., Vasilevskaya T. I., Pavlovskii N. B., Krinitskaya N. B. Formation of the biochemical composition of fruits of the Ericaceae family (Heathers) when introduced in Belarus, in Parfenov V. I. (ed.). Minsk, Belaruskaia navuka Publ., 2011. 307 p. (in Russian).

9. Karabanov I. A. Flavonoids in the plant world. Minsk, Uradzhai Publ., 1981. 80 p. (in Russian).

\section{Информация об авторах}

Рупасова Жанна Александровна - член-корреспондент, д-р биол. наук, профессор, заведующий лабораторией. Центральный ботанический сад НАН Беларуси (ул. Сурганова, 2в, 220012, г. Минск, Республика Беларусь). E-mail: J.Rupasova@cbg.org.by.

Гаранович Игорь Михайлович - канд. биол. наук, вед. науч. сотрудник. Центральный ботанический сад НАН Беларуси (ул. Сурганова, 2в, 220012, г. Минск, Республика Беларусь). E-mail: bel.dendr@gmail.com.

Шпитальная Тамара Васильевна - канд. биол. наук, заведующий лабораторией. Центральный ботанический сад НАН Беларуси (ул. Сурганова, 2в, 220012, г. Минск, Республика Беларусь). E-mail: t.shpitalnaya@cbg.org.by.

\section{Information about the authors}

Zhanna A. Rupasova - Corresponding Member, D. Sc. (Biol.), Professor, Head of the Laboratory. Central Botanic Garden of the National Academy of Sciences of Belarus (2v, Surganov Str., 220072, Minsk, Republic of Belarus). E-mail: J.Rupasova@cbg.org.by.

Igor M. Garanovich - Ph. D. (Biol.), Leading reseacher. Central Botanic Garden of the National Academy of Sciences of Belarus (2v, Surganov Str., 220072, Minsk, Republic of Belarus). E-mail: bel.dendr@gmail.com.

Tamara V. Shpitalnaya - Ph. D. (Biol.), Head of the Laboratory. Central Botanic Garden of the National Academy of Sciences of Belarus (2v, Surganov Str., 220072, Minsk, Republic of Belarus). E-mail: t.shpitalnaya@cbg.org.by. 
Василевская Тамара Ивановна - канд. биол. наук, ст. науч. сотрудник. Центральный ботанический сад НАН Беларуси (ул. Сурганова, 2в, 220012, г. Минск, Республика Беларусь). E-mail: T.Vasileuskaya@cbg.org.by.

Криницкая Наталья Болеславовна - науч. сотрудник. Центральный ботанический сад НАН Беларуси (ул. Сурганова, 2в, 220012, г. Минск, Республика Беларусь).

Фролова Людмила Владимировна - канд. с/х наук, заведующий лабораторией. Институт плодоводства (ул. Ковалева, 2, 223013, агр. Самохваловичи, Республика Беларусь).

Архаров Александр Владимирович - вед. инженер. Центральный ботанический сад НАН Беларуси (ул. Сурганова, 2в, 220012, г. Минск, Республика Беларусь). E-mail: bel.dendr@gmail.com.
Tamara I. Vasilevskaya - Ph. D. (Biol.), Senior researcher. Central Botanic Garden of the National Academy of Sciences of Belarus (2v, Surganov Str., 220072, Minsk, Republic of Belarus). E-mail: T.Vasileuskaya@cbg.org.by.

Natalia B. Krinitskaya - Researcher. Central Botanic Garden of the National Academy of Sciences of Belarus (2v, Surganov Str., 220072, Minsk, Republic of Belarus).

Ludmila V. Frolova - Ph. D. (Agricult.), Head of the Laboratory. Institute for Fruit Growing (2, Kovaleva Str., 223013, Samochvalovichi, Republic of Belarus).

Aleksander V. Arkharov - Management Engineer. Central Botanic Garden of the National Academy of Sciences of Belarus (2v, Surganov Str., 220072, Minsk, Republic of Belarus). E-mail: bel.dendr@gmail.com. 